\title{
Cross-language message- and word-level transfer effects in bilingual text processing
}

\author{
Deanna C. Friesen And Debra Jared \\ University of Western Ontario, London, Ontario, Canada
}

\begin{abstract}
The present study examined the nature of the mental representations bilinguals form when reading a text and to what extent they are language specific. English-French bilinguals read five pairs of passages in succession while their eye movements were tracked. Dependent measures were overall reading times on second passages and fixation latencies on target cognates embedded in second passages. The first passage was (1) identical to the second passage in the pair, (2) related in content only (i.e., a translation), (3) related in content and some words (i.e., translation with cognates), (4) related in words only (i.e., different content with the same cognates), or (5) unrelated. There was substantial cross-language facilitation for passages that shared meaning, but the amount of transfer was less than that for identical passages, indicating that memory representations are largely meaning based but do contain some information about surface form. Cross-language transfer for cognates was observed but depended on the skill of the bilinguals in their second language, the direction of transfer, and whether the passages shared meaning. These results are discussed in relation to Raney's (2003) model of text representation.
\end{abstract}

Substantial evidence exists demonstrating that exposure to print is a crucial factor in the development of both automatic word recognition skills and good reading comprehension skills (Chateau \& Jared, 2000; Cunningham \& Stanovich, 1990; Stanovich, 1986; Stanovich \& Cunningham, 1992, 1993; Stanovich \& West, 1989). For bilinguals, whose exposure to print is often divided between their two languages, this finding raises an important question: Does exposure to print in one language facilitate reading performance in the other language? The answer to this question not only has practical implications for the education of bilinguals, but also has theoretical implications concerning whether the representations and processes involved in reading are common between a bilingual's two languages or whether they are distinct.

Much of the research on bilingual reading has focused on word recognition and sentence processing (see Kroll \& De Groot, 2005). There has been much less research investigating the representations and processes involved when bilinguals read whole texts (for a review, see Raney, Obeidallah, \& Miura, 2002). The present study examined whether bilinguals draw on knowledge from a prior experience with a text in one of their languages when reading a text in the other language and, if so, what aspect of the initial text facilitates subsequent reading. Although bilinguals do not typically read a text in one of their languages and then the other, a repeated-reading paradigm can provide evidence concerning the nature of the representations formed when a text is read and to what extent they are language specific.

A repeated-reading paradigm has been used by several researchers to investigate the nature of text representations in monolingual readers (e.g., Bourassa, Levy, Dowin, \& Casey, 1998; Carr \& Brown, 1990; Levy \& Burns, 1990; Raney, Therriault, \& Minkoff, 2000). In this paradigm, participants read pairs of passages that are alike in some way. Researchers then make inferences about what type of information is encoded in the memory representation of an initial text on the basis of whether that text facilitates a subsequent reading of the other text in the pair. For example, a pair of passages could overlap in vocabulary, but not in message. A finding of savings in reading time on the second passage, as compared with a control condition in which the first passage does not share vocabulary with the second, would suggest that the memory representation of the first passage contains word-specific information. Such a finding is called a transfer effect or a repetition effect. Applying this to bilinguals, we can ask whether pairs of passages that are in different languages but that contain the same set of cognates (i.e., words that have the same meaning and orthography in two languages, such as table in English and French) produce transfer effects. If cognates in the second passage are read more quickly when the first passage includes those cognates than when it does not, this would imply that the word representations from the first passage are not specific to the language of the text.

\section{Transfer Effects in Monolinguals}

In the monolingual literature on text repetition effects, researchers have investigated whether the meaning of a text and the wording of a text transfer independently. Specifically, a key issue is whether rereading benefits for words are observed across different meaning contexts. Carr, Brown,

D. Jared,djjared@uwo.ca 
and Charalambous (1989) found evidence that they are and suggested that transfer effects are due to the priming of abstract word-level representations. In contrast, Levy, Barnes, and Martin (1993) provided evidence that wordlevel transfer depends on the similarity of the message in the two passages. They argued that readers form an episodic memory trace of a passage in which the text meaning is the distinguishing feature of the representation. The surface form is bound to the text's meaning, and therefore, wordlevel transfer is predicted to occur only when the meaning of the text is reinstated in a subsequent reading.

Raney (2003) proposed a context-dependent representation model based on Kintsch and van Dijk's (1978) theory of text processing that reconciles these conflicting views. In Kintsch and van Dijk's model, there are three separate levels of text representation. These representations are hierarchical in nature with surface form, textbase, and situation model comprising the levels from lowest to highest, respectively. The surface form of a text includes the wording and its syntax. The textbase is the meaning of the text represented in the form of propositions. These propositions are not contingent on the exact wording of the text, but only on the meaning. Finally, the situation model is drawn from the textbase and a reader's background knowledge to form an overall interpretation of the text. It also includes any inferences drawn from the text. Although these levels of text representation build on one another, they are assumed to be different levels of representation (Fletcher \& Chrysler, 1990).

Raney's (2003) context-dependent representation model extends Kintsch and van Dijk's (1978) theory by proposing that the three levels of representation reflect different degrees of dependence on the passage context. Surface form and textbase representations are assumed to be independent of context, whereas a well-developed situation model, which binds together the surface form and textbase, is a context-dependent representation. Transfer effects depend, therefore, on the degree to which a situation model is formed. When a reader is able to form a good situation model, the surface form and the textbase are integrated into a holistic text representation and become context dependent. Repetition effects will occur only if the situation model produced upon reading the first text overlaps with that for the second text, and the size of the repetition effect is expected to increase as the overlap between situation models, textbases, and surface forms increases. Because the representation of the surface form is dependent on the context, the lexical components of the text cannot independently confer processing benefits on a subsequent text. However, if no situation model or a poor situation model is developed, the surface form and textbase are not tightly bound to the text representation and thus remain context independent. Consequently, lexical components are free to transfer regardless of contextual similarity between readings.

The context-dependent representation model can account both for research that has shown context-independent lexical transfer (e.g., Carr et al., 1989) and for research that has shown lexical transfer only when pairs of texts shared meaning (e.g., Levy \& Burns, 1990). In Carr et al.'s study, participants were asked to read passages aloud as accurately as possible, but Levy and Burns's participants were instructed to read silently for meaning. According to the context-dependent representation model, task instructions that do not emphasize reading for meaning may enhance memory for surface form and produce contextindependent repetition effects, whereas task instructions that encourage reading for meaning will be expected to enhance memory for the situation model and produce context-dependent repetition effects.

Furthermore, the context-dependent representation model is able to account for differences in the pattern of transfer effects that Faulkner and Levy $(1994,1999)$ observed for good and poor readers (Raney, 2003). When readers are skilled, they are able to devote their resources to higher level processes, such as text integration and comprehension. Consequently, they form a good situation model to which the textbase and surface form are bound, and lexical transfer is observed only when texts overlap in meaning. In contrast, poor readers devote more of their attention to decoding the text than to comprehending the text (Bourassa et al., 1998; Zwaan \& Brown, 1996), and as a result, their ability to form a situation model may be compromised. The context-dependent representation model, therefore, expects transfer to be observed not only when texts share meaning, but also when texts just share words.

\section{Cross-Language Transfer}

These findings from the monolingual literature suggest that the nature of cross-language transfer effects may depend on the extent to which a bilingual is able to form a situation model of the initial text in a pair. When bilingual participants are instructed to read passages for meaning, their ability to form a situation model of the first passage will depend to a large degree on their fluency in the language of the passage. Cross-language transfer effects in fluent bilinguals might be expected to be more dependent on the similarity of the messages in a pair of passages than are transfer effects in less fluent bilinguals.

Another finding from the monolingual literature that is relevant to cross-language transfer is that transfer effects are smaller when second passages are paraphrases of the first than when they are identical (Levy et al., 1993; Raney et al., 2000). Passages that are paraphrases of one another would result in similar situation models and similar textbase representations but would differ in their surface form representations. A reduced transfer effect for paraphrased passages indicates that text representations typically contain information about the orthographic forms of words (surface form) and not just about word meanings (textbase). Further evidence that text representations contain surface form information comes from Raney et al.'s (2000) finding that second-passage words had shorter fixation latencies when they were identical to words in the first passage than when they were synonyms. However, this effect was attenuated when much of the surface form differed between passages, as compared with when most was the same, suggesting that participants were less likely to recruit the surface form information when second passages looked quite different from the first. Raney (2003) noted 
that a potential limitation of using paraphrases, however, is that readers sometimes report noticing differences between texts, which could lead to a focus on wording and slower reading of paraphrased passages.

Passages that are translations of one another naturally differ in their surface form but would result in the same (or very similar) textbase and situation models being created if, indeed, these textbase representations and situation models are independent of the specific language of a text. If translations are analogous to paraphrases, transfer effects should be observed for passages that are translations of one another, although these effects are expected to be smaller than transfer effects for identical passages. An interesting question is whether transfer effects for cognates in translated passages are larger than those for translation equivalents - that is, whether there is transfer of word-level surface form when most of the surface form of the second passage differs from that of the first. Raney et al.'s (2000) finding for monolinguals of little difference in fixation times between repeated words and synonyms in second passages that were paraphrases of the first suggests that cross-language surface form transfer may not occur, at least when readers are fluent in the language of the texts. Less fluent bilinguals, though, might be more likely to produce surface form transfer. However, it is unclear whether cognates are free to transfer across passages in different languages or whether they are bound to the language context in which they originally appeared.

Work in the field of bilingual word recognition supports the idea that a cognate's representation is activated from either language. For example, Dijkstra, Van Jaarsveld, and Ten Brinke (1998) found that Dutch-English bilinguals responded more quickly to cognates in an English lexical decision task than to matched English control words (see also Gerard \& Scarborough, 1989; Lemhöfer \& Dijkstra, 2004; van Hell \& Dijkstra, 2002). Furthermore, near-identical cognates produce repetition priming effects comparable to those from same-language morphological primes (Cristoffanini, Kirsner, \& Milech, 1986; Sánchez-Casas \& García-Albea, 2005). These findings from studies of words in isolation suggest that it is plausible that cognates might be free to transfer across passages in different languages. However, it is also possible that the strong language context of a passage might serve to limit transfer.

There is a study that has examined cross-language transfer effects in text reading, although it has not been published. Raney, Atilano, and Gomez (1996, as cited in Raney, 2003; Raney et al., 2002) had English-Spanish bilinguals read pairs of passages that were translations of one another while their eye movements were monitored. In one condition, the first passages were in English, and the second passages were in Spanish; in another condition, the first passages were in Spanish, and the second passages were in English. In both conditions, fluent bilinguals produced cross-language transfer effects for cognates; however, a similar-sized transfer effect was observed for matched noncognates (translation equivalents), suggesting that transfer effects for cognates were due to shared meaning across languages, and not to shared or- thographic form. Less fluent bilinguals produced similar results when the first passages were in Spanish and the second passages were in English. However, cognates were read more quickly than noncognates in Spanish second passages that were preceded by their English translation. This study provides evidence for cross-language transfer of meaning (or textbase) in the absence of repeated surface form, suggesting that surface and textbase representations are, indeed, distinct levels of text representation. However, there was only limited evidence for cross-language transfer of surface form when passages overlapped in message. A possible reason that cross-language word-level transfer effects were not more evident may have been because the experiment used a between-word manipulation. Cognates and noncognates may not have been precisely matched for difficulty, nor were they located in the same place in the passage. Furthermore, most cognates differed by at least a letter in English and Spanish, which may have limited cognate transfer effects. The researchers did not examine cross-language cognate transfer effects for pairs of passages that did not overlap in message.

\section{The Present Study}

The present study examined whether exposure to a text in one language facilitates reading in a bilingual's other language and, if so, what aspect of the initial text facilitates subsequent reading. We investigated cross-language transfer using both a global dependent measure (overall reading time on second passages) and a local dependent measure (fixation durations on cognates in second passages). The global measure is informative regarding message-level transfer, whereas the latter is informative regarding word-level transfer.

Message-level transfer is typically observed in the monolingual literature (e.g., Levy et al., 1995). Of interest here is how message-level transfer is affected by a change in language across a pair of passages. There are three alternative outcomes. If memory representations of text are entirely meaning based and neutral with respect to language, transfer should occur from a text to its translation. Indeed, the second text in a pair should be read as quickly when it is preceded by its translation as when it is preceded by the identical passage. Conversely, if text memory representations are entirely language specific (an unlikely possibility), no cross-language transfer effects should be observed. That is, second passages should be read as quickly when preceded by a translation as when preceded by an unrelated passage. Finally, if the memory representation is meaning based but contains some language-specific information (e.g., Levy et al., 1993; Raney, 2003), second passages should be read more slowly when they are preceded by their translations than when preceded by an identical passage, but more quickly than when preceded by an unrelated passage. Because this last alternative is consistent with the paraphrase results in the monolingual literature mentioned earlier (Levy et al., 1993; Raney et al., 2000), it was the expected outcome in the present study.

Of particular interest in the present study was determining the conditions, if any, under which cross-language 
word-level transfer would be found. We examined whether cognates in the initial text would facilitate subsequent reading of the same words in a different-language text. The broadest transfer that could occur would be if cognates in a text facilitated the reading of cognates in a second text that differed in both language and message. We investigated whether such transfer would occur by comparing cognate reading times in second passages when these were preceded by passages that overlapped with the second passage in cognates only (not in language or message) and when they were preceded by completely unrelated other-language passages. If second-passage cognates were read more quickly when the first passage contained the same cognates, this would provide evidence for broad cross-language word-level transfer. Such a finding might be predicted by Carr et al.'s (1989) abstractionist view, if members of a cognate pair share a word-level representation, but would not be expected in Levy et al.'s (1993) episodic view. Raney et al. (1996, as cited in Raney, 2003; Raney et al., 2002) did not include such a condition; nonetheless, on the basis of Raney's (2003) theory and findings from the monolingual literature, such transfer might be expected only when readers are unable to form a good situation model, such as when the first passage of a pair is in a language in which a bilingual is not very proficient.

In the monolingual literature, word-level transfer is more likely to occur when the message of the initial text is repeated (Levy et al., 1993). Cross-language word-level transfer, then, might be observed when pairs of passages are translations of one another. We examined meaning transfer at the word level by comparing reading times for cognates in second passages when those passages had been preceded by a translation that contained synonyms of those cognates and when they had been preceded by an unrelated passage. To examine more specifically whether the locus of any word-level transfer could be attributed to orthographic repetition, rather than to repeated meaning, cognate reading times in second passages were compared when they were preceded by a translation with cognates and when they were preceded by a translation that contained synonyms of the cognates. Although Raney et al. (1996, as cited in Raney et al., 2002) did not observe transfer of word-specific orthography for fluent bilinguals, or for less fluent bilinguals when the second passage was in their stronger language (i.e., cognates were not read more quickly than noncognates), in a more sensitive design in which cognates serve as their own controls, transfer effects might be evident.

Finally, the present study also looked at the impact of a change in language context on cognate transfer effects. We examined whether cognates in second passages were read more slowly when preceded by a translation that also contained those cognates than when preceded by an identical passage.

The participants in the study read five pairs of passages (see Figure 1). Each second passage contained 20 target cognates. The second passage was preceded either by an identical passage or by one of four passages in the other language. Cross-language initial passages were translations containing the 20 target cognates, translations with synonyms in place of the cognates, texts on a different topic but containing the same 20 cognates as the second passage, or texts completely unrelated to the second passage. Dependent measures were overall reading times on the second passages and fixation latencies on the 20 target cognates in the second passages. Table 1 shows the specific comparisons between levels of the initial-passage type that were of interest. The participants were university students who were native speakers of English and who could also read French. Half had very good French reading comprehension ability, and half were weaker in French reading ability, in order to examine the impact of ability to form a situation model on cross-language transfer.

\section{METHOD}

\section{Participants}

One hundred undergraduate students from the University of Western Ontario participated in the experiment. All the participants indicated that English was their first language and French was their second language. On the basis of their performance on a French reading comprehension test, 50 participants were classified as more skilled bilinguals, and 50 were classified as less skilled bilinguals. The participants received course credit or were paid for their involvement in the study.

\section{Materials}

The Reading Comprehension Test of the Senior French Proficiency Test Package for French Immersion (Second Language Institute and Modern Language Centre, 1985-1988) was used to assess the participants' understanding of written French. It consisted of three French passages, each with corresponding multiple-choice questions. There were 19 questions in total on the test. The participants who scored between 12 and 16 were classified as more skilled bilinguals (none of our participants scored higher than 16), and the participants who scored between 5 and 9 were classified as less skilled bilinguals. Due to the fact that the task was a subtest of a test battery, no individual norms were available. A questionnaire was used to gain an understanding of the participants' language background.

To create the experimental materials, five passages were first written in English. These texts served as the second passage in each pair for the English test passage condition. The test passages were then translated into French to serve as the test passages in the French test passage condition. To confirm the accuracy of the translations, the French passages were then translated back into English by a FrenchEnglish bilingual who did not see the original English passages. We had five different test passages so that the participants could see each of the five types of passage pairs without seeing any test passage twice. Each passage had a five-paragraph structure with four English-French target cognates in each paragraph. The mean length of the English test passages was 341 words (range: $322-352$ words). The mean length of the French test passages was 357 words (range: 331-382 words). Of the 100 cognates used in the experiment, 93 were identical cognates. Seven close cognates, differing slightly in orthography, were also employed (e.g., philosophy and philosophie). Given the large number of English-French cognates that exist, having 20 cognates in passages of this length would not be unusual in natural texts. The mean frequencies of the target cognates were 52.8 words per million in English (Baayen, Piepenbrock, \& Van Rijn, 1993 ) and 84.9 words per million in French (Content, Mousty, \& Radeau, 1990). An example of a passage set can be found in Appendix A. The test passages also served as initial passages in both the identical-passage condition and the translation-with-cognates condition. For example, if the test passage was in English, then in the identical condition, it was preceded by itself, and in the translationwith-cognates condition it was preceded by the French version of the passage. 


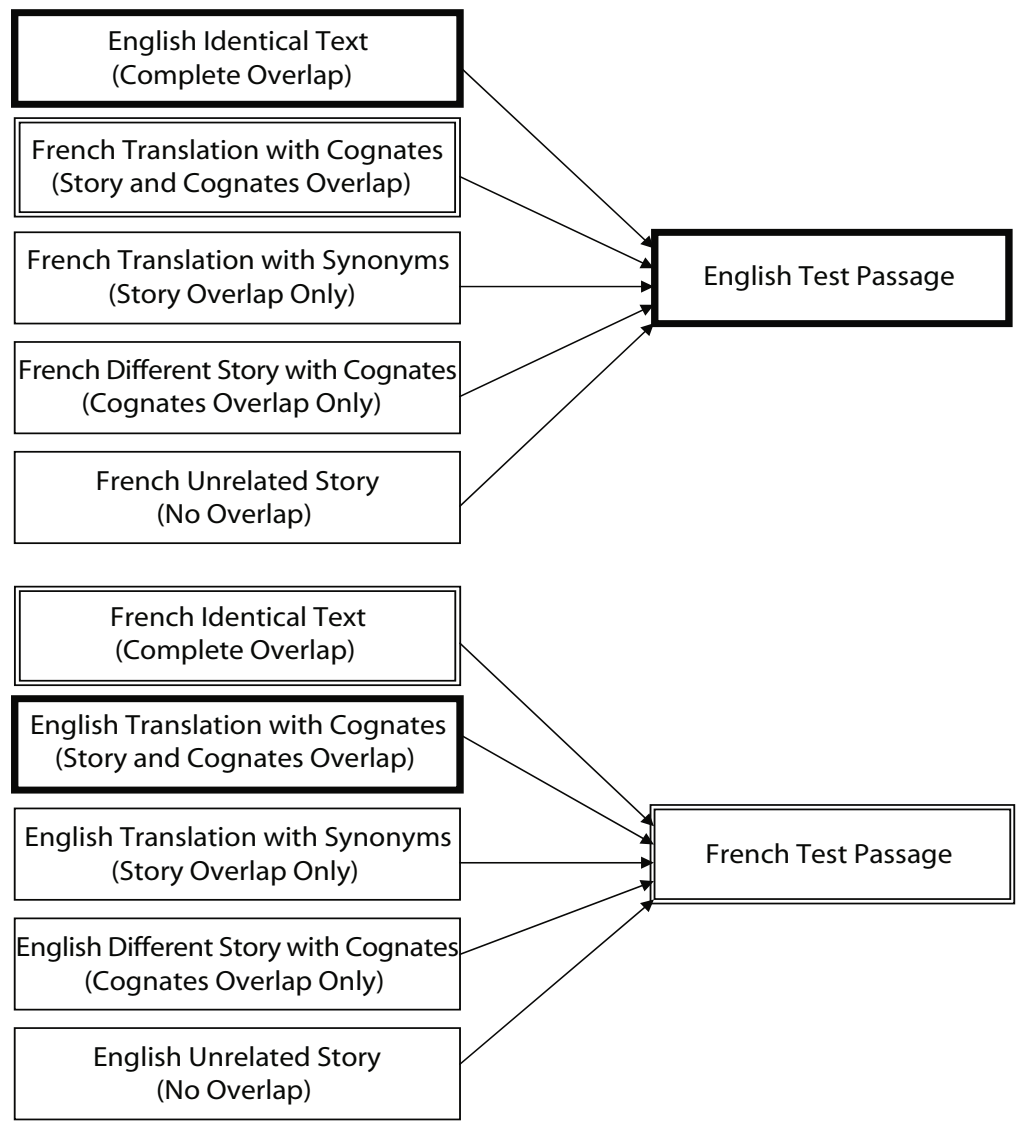

Figure 1. Experimental design. The parentheses indicate the type of overlap that existed between the initial passage and the test passage. All analyses were performed on the test passages, which were always read second in a pair. The boxes in bold or with double lines indicate which texts were the same across the experiment. For each second passage, an individual participant saw only one of the first-passage types.

Next, the three other types of initial passages were developed. To create the passages for the translation-with-synonyms condition, the cognates in the French and English test passages were replaced with synonyms of those cognates. The synonyms were placed in the same location in the text as the cognates they replaced. Three criteria were employed when a synonym was chosen. First, they had to be synonymous with the meaning of the cognates within the context of the passage. Second, the synonyms had to be words that were likely to be known by the participants. Third, attempts were made to ensure that synonyms were chosen that were not cognates themselves. The reason for this restriction was to ensure that any transfer observed was in fact interlingual.

To create initial passages for the different-story-with-cognates condition, the 20 target cognates in each test passage were incorporated into a passage on a different topic. For example, one test passage was about a salmon's life cycle, whereas the corresponding initial passage contained the same 20 target cognates but was on the subject of economics. These initial passages were of similar length to the test passages and maintained the five-paragraph structure. The cognates were employed in the same semantic sense as in the corresponding English passage. However, the cognates were not in the same physical location in the test passages, since we wished to address broad, rather than position-specific, transfer. Both English and French versions of each of these initial passages were created. The participants read, for example, the initial passage about economics in French and the test passage about salmon in English.
Finally, a text was created in both English and French for use as the unrelated initial passage. This passage did not overlap in content or in the use of cognates with any of the test passages. Due to the nature of the relationship between French and English, cognates were present in the unrelated passage. Although a complete lack of vocabulary overlap between passages was not possible, the use of target cognates and their synonyms was avoided.

Multiple-choice comprehension questions were developed for each passage in order to encourage the participants to read the passages for meaning. The initial texts had three multiple-choice questions each (see Appendix B). These questions did not focus on the target cognates. Each test passage had five multiple-choice questions. Multiple-choice questions were presented in the same language as the text to which they pertained.

A Red II remote eyetracker (Sensorimotor Instruments, Cambridge, MA) was employed to measure the participants' eye movements. The eyetracker's sampling rate was $60 \mathrm{~Hz}$. Text was presented at 1,024 $\times 768$ resolution on a 17 -in. LCD monitor. Texts were single spaced in Times New Roman with a 24-point font size. Each paragraph of a passage was displayed separately.

\section{Procedure}

Potential participants were given $30 \mathrm{~min}$ to complete the French reading comprehension test. Next, they were asked to complete the language experience questionnaire. Those who scored between 5 and 9 or 12 and above on the reading comprehension test and who 
Table 1

Comparisons Made in the Analyses and the Type of Transfer Addressed by Each

\begin{tabular}{ll}
\hline \multicolumn{1}{c}{ Comparison } & \multicolumn{1}{c}{ Type of Transfer } \\
\hline $\begin{array}{l}\text { Overall reading time on second passages } \\
\text { Identical versus unrelated } \\
\text { Translation with synonyms versus unrelated } \\
\text { Identical versus translation with cognates }\end{array}$ & $\begin{array}{l}\text { Mithin-language transfer } \\
\text { cross-language message-level transfer } \\
\text { within-language versus cross-language message-level transfer }\end{array}$ \\
$\begin{array}{l}\text { Fixation durations on target cognates } \\
\text { Identical versus unrelated }\end{array}$ & $\begin{array}{l}\text { Word-Level Transfer } \\
\text { Different story with cognates versus unrelated } \\
\text { Translation with synonyms versus unrelated } \\
\text { Translation with cognates versus translation with synonyms } \\
\text { Identical versus translation with cognates }\end{array}$ \\
\hline
\end{tabular}

indicated on the language experience questionnaire that their first language was English were invited to return for the experimental session.

In the experimental session, each participant read five pairs of passages. The second passages that a participant read were always in the same language (i.e., English or French). Half of the participants read English test passages, and half read French test passages. For an individual participant, each of the five test passages was preceded by a different one of the five initial-passage types (identical, translation with cognates, translation with synonyms, different story with cognates, and unrelated). The presentation of stimuli was counterbalanced so that, across participants, each test passage was paired equally often with each initial-passage type and each of the five initial-passage conditions appeared equally often in the first to fifth positions within the testing session.

All verbal and written instructions were given in English. The participants were seated so that their eyes were $50-60 \mathrm{~cm}$ from the computer screen. To ensure that accurate eye-tracking data were recorded, the participants were instructed to sit as still as possible throughout the experimental session. The participants' left hand was positioned over the space bar, and their right hand was positioned over the number pad. At the start of the session, the eyetracker was calibrated to follow the participant's left eye and was recalibrated as needed between trials. The participants were instructed to read normally and for meaning and were told that there would be comprehension questions following each text. The participants were aware that they would be reading pairs of passages and that these passages would be in either English or French. However, they were not informed of the relationships between the passages in a pair. The passages were displayed on the computer screen one paragraph at a time, and the participants advanced through the passage paragraphs by pressing the space bar. Reading times for each paragraph were recorded from the time the paragraph appeared until the space bar was pressed. Following each initial passage, the participants answered three multiple-choice questions about the passage. They indicated their response to each question by pressing the 1, 2, and 3 keys on the number pad. After each question, the participants were informed about how they did on that question. After the final multiple-choice question, the participants proceeded to the second passage and its five corresponding questions. This procedure was repeated until the participants had read five pairs of passages.

\section{RESULTS}

Responses on the language experience questionnaire established that the participants were English-dominant English-French bilinguals (see Table 2). Of particular interest, and consistent with the French reading comprehension test results, the more skilled bilinguals rated their
French reading skill significantly higher than did the less skilled bilinguals $[t(96)=5.50, p<.001]$. Furthermore, the skilled bilinguals performed significantly better than the less skilled bilinguals on the comprehension questions that followed the French initial passages $[t(48)=$ $2.89, p<.01]$. This superior comprehension of French initial passages is evidence that the skilled bilingual group was better able to form a situation model of the French initial passages than were the less skilled bilinguals. The two subgroups within each French ability group (test passages in English or in French) did not differ significantly on French reading test scores or on the self-report measures of French proficiency. Furthermore, the more skilled and less skilled bilinguals did not differ in their English reading ability. Comparisons of initial-passage reading times and comprehension question performance for the two groups of participants who saw four English first passages revealed no significant differences between the more skilled and the less skilled bilinguals (both $p \mathrm{~s}>$ .10). Initial-passage reading times for the two groups of participants who saw only one first passage in English also did not differ significantly $(p>.10)$. Because skilled and less skilled bilinguals performed similarly on English passages when they were the first passages in the pairs, any differences between bilingual groups on English passages when they were the second passages in the pairs can be attributed to their having read a French passage first.

Three variables were included in all the analyses of transfer effects. Initial-passage type was a within-subjects variable, and French language skill and test passage language were between-subjects variables. All analyses were performed on reading times for second passages. Specifically, the dependent measures were overall second-passage reading times, gaze durations on target cognates, and total fixation times on target cognates. Note that because each test passage occurred equally often in each experimental condition, there was no confounding of test passage characteristics and condition.

\section{Message-Level Transfer Effects}

We used overall second-passage reading times to assess within- and cross-language message-level transfer (see Table 3). A series of ANOVAs were conducted using only 
Table 2

French Fluency Ratings, Age of Acquisition, School Experience, and French Reading Comprehension Score for the More Skilled and Less Skilled Bilinguals

\begin{tabular}{|c|c|c|c|c|}
\hline \multirow[b]{2}{*}{ Task } & \multicolumn{2}{|c|}{$\begin{array}{c}\text { More Skilled } \\
\text { Bilinguals } \\
\end{array}$} & \multicolumn{2}{|c|}{$\begin{array}{c}\text { Less Skilled } \\
\text { Bilinguals } \\
\end{array}$} \\
\hline & $M$ & $S D$ & $M$ & $S D$ \\
\hline French reading comprehension (out of 19) & 13.84 & 1.46 & 7.36 & 1.26 \\
\hline \multicolumn{5}{|l|}{ French fluency ratings (scale, 1 to 10 ) } \\
\hline Understanding & 7.89 & 1.59 & 6.47 & 1.89 \\
\hline Speaking & 7.13 & 1.95 & 5.68 & 2.20 \\
\hline Reading & 7.84 & 1.24 & 6.12 & 1.80 \\
\hline Writing & 6.81 & 1.72 & 5.14 & 2.07 \\
\hline \multicolumn{5}{|l|}{ Age began French skills (in years) } \\
\hline Understanding & 6.49 & 3.49 & 7.48 & 3.23 \\
\hline Speaking & 6.53 & 3.49 & 7.78 & 2.24 \\
\hline Reading & 7.02 & 3.19 & 8.12 & 2.87 \\
\hline Writing & 7.22 & 3.22 & 8.28 & 2.98 \\
\hline \multicolumn{5}{|l|}{ Years of instruction } \\
\hline English only & 2.86 & 2.89 & 2.80 & 2.54 \\
\hline Core French course & 4.38 & 4.18 & 7.04 & 4.17 \\
\hline French immersion & 5.46 & 5.13 & 3.35 & 4.47 \\
\hline French only & 1.24 & 2.88 & 0.53 & 1.71 \\
\hline French school with an English course & 1.36 & 2.99 & 0.31 & 1.37 \\
\hline
\end{tabular}

the levels of the initial-passage type variable that spoke to the question of message-level transfer (see Table 1). Note that overall reading time was an inappropriate measure by which to address questions of surface-level transfer in the present study, since when cognates were repeated between translations, they constituted, on average, only $5 \%$ of the words appearing in the texts.

Identical versus unrelated. A 2 (identical vs. unrelated) $\times 2$ (more skilled vs. less skilled) $\times 2$ (English vs. French) ANOVA examined whether there was any withinlanguage transfer across repeated readings. A significant main effect of initial-passage type was found $[F(1,96)=$ 97.31, $\left.M S_{\mathrm{e}}=491, p<.001\right]$. The participants read second passages more quickly when they were preceded by an identical passage than when they were preceded by an unrelated passage in the participant's other language. Main effects of both French language skill $[F(1,96)=$
6.42, $\left.M S_{\mathrm{e}}=1,244, p<.05\right]$ and test passage language $\left[F(1,96)=68.71, M S_{\mathrm{e}}=1,244, p<.001\right]$ were significant. Specifically, the more skilled bilinguals read the test passages more quickly than did the less skilled bilinguals, and test passages in English were read more quickly than test passages in French. (In all the subsequent analyses, there were significant main effects of French language skill and test passage language in the same direction. To simplify the presentation of our analyses, these effects will not be reported.) None of the possible interactions between variables were significant.

Translation with synonyms versus unrelated. Cross-language message-level transfer was assessed by comparing the translation-with-synonyms condition with the unrelated condition. A 2 (translation with synonyms vs. unrelated) $\times 2$ (less skilled vs. more skilled) $\times 2$ (English vs. French) ANOVA revealed a significant main ef-

Table 3

Mean Overall Reading Time (in Seconds) on English and French Second Passages As a Function of Initial Passage Type and French Language Skill

\begin{tabular}{|c|c|c|c|c|}
\hline \multirow[b]{2}{*}{ Initial Passage Type } & \multicolumn{2}{|c|}{$\begin{array}{c}\text { English Second } \\
\text { Passages }\end{array}$} & \multicolumn{2}{|c|}{$\begin{array}{c}\text { French Second } \\
\text { Passages }\end{array}$} \\
\hline & $M$ & $S E$ & $M$ & $S E$ \\
\hline \multicolumn{5}{|l|}{ More skilled in French } \\
\hline Identical & 72 & 3.4 & 102 & 5.6 \\
\hline Translation with cognates & 77 & 2.5 & 111 & 5.1 \\
\hline Translation with synonyms & 78 & 4.0 & 109 & 6.5 \\
\hline Different story with cognates & 89 & 3.4 & 140 & 7.9 \\
\hline Unrelated & 92 & 3.9 & 139 & 7.3 \\
\hline \multicolumn{5}{|l|}{ Less skilled in French } \\
\hline Identical & 76 & 4.5 & 119 & 6.6 \\
\hline Translation with cognates & 91 & 3.5 & 118 & 7.2 \\
\hline Translation with synonyms & 94 & 4.3 & 121 & 7.9 \\
\hline Different story with cognates & 107 & 5.2 & 149 & 8.2 \\
\hline Unrelated & 108 & 5.8 & 153 & 8.2 \\
\hline
\end{tabular}


Table 4

Mean Gaze Duration on Target Cognates (in Milliseconds) in English and French Second Passages As a Function of Initial-Passage Type and French Language Skill

\begin{tabular}{|c|c|c|c|c|}
\hline \multirow[b]{2}{*}{ Initial-Passage Type } & \multicolumn{2}{|c|}{$\begin{array}{l}\text { English Second } \\
\text { Passages }\end{array}$} & \multicolumn{2}{|c|}{$\begin{array}{l}\text { French Second } \\
\text { Passages }\end{array}$} \\
\hline & $M$ & $S E$ & $M$ & $S E$ \\
\hline \multicolumn{5}{|l|}{ More skilled in French } \\
\hline Identical & 202 & 8.1 & 226 & 12.7 \\
\hline Translation with cognates & 222 & 8.8 & 255 & 12.5 \\
\hline Translation with synonyms & 226 & 8.5 & 236 & 14.3 \\
\hline Different story with cognates & 227 & 11.7 & 243 & 12.2 \\
\hline Unrelated & 246 & 12.0 & 255 & 10.7 \\
\hline \multicolumn{5}{|l|}{ Less skilled in French } \\
\hline Identical & 229 & 8.0 & 264 & 11.6 \\
\hline Translation with cognates & 247 & 9.5 & 259 & 11.0 \\
\hline Translation with synonyms & 252 & 7.4 & 281 & 13.3 \\
\hline Different story with cognates & 269 & 7.2 & 284 & 13.7 \\
\hline Unrelated & 250 & 5.7 & 291 & 12.1 \\
\hline
\end{tabular}

fect of initial-passage type $\left[F(1,96)=41.72, M S_{\mathrm{e}}=604\right.$, $p<.001]$. Second-passage reading times were shorter when initial passages were translations with synonyms than when they were unrelated. There was also a significant interaction of initial-passage type and test passage language $\left[F(1,96)=6.25, M S_{\mathrm{e}}=604, p<.05\right]$, indicating that the facilitation was greater when the second passage was French than when it was English. NewmanKeuls comparisons revealed significant facilitation effects both when second passages were French $[q(2,96)=8.96$, $p<.01]$ and when they were English $[q(2,96)=3.95$, $p<.01]$. No other interactions were significant.

Translation with cognates versus identical. The final question concerns whether cross-language messagelevel transfer differs in magnitude from within-language transfer. A 2 (translation with cognates vs. identical) $\times 2$ (more skilled vs. less skilled) $\times 2$ (English vs. French) ANOVA produced a main effect of initial-passage type $\left[F(1,96)=12.87, M S_{\mathrm{e}}=208, p<.01\right]$. Test passages were read more quickly when preceded by identical passages than when preceded by translations with cognates. There was also a three-way interaction $[F(1,96)=5.76$, $\left.M S_{\mathrm{e}}=208, p<.05\right]$, and therefore, the results for the two skill groups were analyzed separately. An ANOVA of initial-passage type (translation with cognates vs. identical) and test passage language (English vs. French) for the more skilled bilinguals revealed a main effect of initialpassage type $\left[F(1,48)=11.19, M S_{\mathrm{e}}=114, p<.01\right]$ and no significant interaction of initial-passage type and test language $(F<1)$. In other words, regardless of test passage language, more skilled bilinguals read test passages more quickly when they were preceded by an identical passage than when they were preceded by a translation with cognates. In contrast, an interaction of initial-passage type and test passage language was significant in the less skilled bilingual group $\left[F(1,48)=5.30, M S_{\mathrm{e}}=302, p<\right.$ $.05]$. When the test passages were in English, the results were much like those for the more skilled bilinguals. English second passages were read more quickly when they were preceded by an identical passage than when they were preceded by a French translation $[q(2,48)=$ $4.46, p<.01]$. However, reading times for French second passages were no shorter when they were preceded by an identical passage than when they were preceded by an English translation with cognates $[q(2,48)=0.15$, n.s. $]$.

\section{Word-Level Transfer Effects}

In order to assess cross-language word-level transfer, fixation durations on target cognates in second passages were analyzed. Both gaze duration and total time measures were used. Gaze duration was defined as all fixations on a target word before a subsequent fixation on another word was made. This measure was employed to assess the initial processing of the target cognates (see Table 4). Total fixation time was defined as total amount of time spent fixating on target words, including any regressions. This measure was used to index how target words were integrated into the text (see Table 5). In keeping with previous research, all single fixations shorter than $100 \mathrm{msec}$ or greater than 1,000 msec were excluded from the analyses (Pollatsek, Raney, LaGasse, \& Rayner, 1995; Raney \& Rayner, 1995). These cutoffs excluded $8.5 \%$ and $0.03 \%$ of the fixation latencies, respectively. In addition, in order to control for outliers within conditions, any data point that was two and a half standard deviations above a participant's mean was also excluded from the analysis. This cutoff point eliminated $1.8 \%$ and $1.7 \%$ of the fixation latencies for gaze duration and total fixation time, respectively. Across the experiment, $17.4 \%$ of the target words were skipped by the participants. As was the case with cross-language message transfer, only initial-passage conditions that addressed word-level transfer were contrasted, resulting in a series of 2 (initial-passage type) $\times 2$ (French language skill) $\times 2$ (text passage language) ANOVAs. The levels of initial-passage type used in each section are indicated in the headers.

Identical versus unrelated. This comparison examined whether the eye-tracking measures were sensitive enough to detect within-language transfer effects on individual words. There was a significant main effect of 
Table 5

\begin{tabular}{|c|c|c|c|c|}
\hline \multirow[b]{2}{*}{ Initial-Passage Type } & \multicolumn{2}{|c|}{$\begin{array}{l}\text { English Second } \\
\text { Passages }\end{array}$} & \multicolumn{2}{|c|}{$\begin{array}{c}\text { French Second } \\
\text { Passages }\end{array}$} \\
\hline & $M$ & $S E$ & $M$ & $S E$ \\
\hline \multicolumn{5}{|l|}{ More skilled in French } \\
\hline Identical & 311 & 14.1 & 337 & 25.2 \\
\hline Translation with cognates & 325 & 20.4 & 398 & 18.3 \\
\hline Translation with synonyms & 324 & 16.8 & 362 & 22.1 \\
\hline Different story with cognates & 355 & 17.0 & 410 & 23.7 \\
\hline Unrelated & 360 & 15.5 & 434 & 32.1 \\
\hline \multicolumn{5}{|l|}{ Less skilled in French } \\
\hline Identical & 318 & 16.9 & 416 & 22.6 \\
\hline Translation with cognates & 378 & 21.6 & 392 & 25.2 \\
\hline Translation with synonyms & 389 & 18.7 & 443 & 30.7 \\
\hline Different story with cognates & 421 & 18.6 & 478 & 26.0 \\
\hline Unrelated & 388 & 15.4 & 492 & 21.1 \\
\hline
\end{tabular}

initial-passage type for both gaze duration $[F(1,96)=$ $\left.23.09, M S_{\mathrm{e}}=2,010, p<.001\right]$ and total time $[F(1,96)=$ $\left.40.91, M S_{\mathrm{e}}=6,532, p<.001\right]$. None of the interactions were significant.

Different story with cognates versus unrelated In order to evaluate whether the broadest type of crosslanguage word-level transfer occurs (i.e., across different message contexts), the different-story-with-cognates condition and the unrelated condition were contrasted. For both gaze duration and total time, none of the main effects or interactions were significant. Nonetheless, because our hypothesis was that only the less skilled bilinguals in the English second-passage condition would demonstrate an effect of initial-passage type, planned comparisons were performed. The less skilled bilinguals had significantly longer gaze durations on cognates in English second passages when they had previously encountered the cognates in a different story in French than when they had not seen the cognates in the initial passage $[t(24)=2.38, p<.05]$. The difference approached significance in the total time measure but was not significant $[t(24)=1.77, p=.09]$.

Translation with synonyms versus unrelated. This comparison examined whether cross-language meaning transfer effects can be observed on individual words. The main effect of initial-passage type approached significance for gaze duration $\left[F(1,96)=3.51, M S_{\mathrm{e}}=1,988\right.$, $p<.07]$ and was significant for total time $[F(1,96)=$ $\left.8.98, M S_{\mathrm{e}}=8,331, p<.01\right]$. None of the interactions were significant.

Translation with cognates versus translation with synonyms. This comparison addressed whether there is cross-language transfer for orthographic form beyond any benefit of repeated meaning. There was no main effect of initial-passage type in either the gaze duration or the total time measure $[F \mathrm{~s}<1]$. The interaction of initial-passage type and skill approached significance for gaze duration $\left[F(1,96)=2.82, M S_{\mathrm{e}}=1,930, p=.09\right]$ and was significant for total time $\left[F(1,96)=5.25, M S_{\mathrm{e}}=5,821, p<\right.$ $.05]$. Less skilled bilinguals tended to have shorter fixation durations on cognates in the second passage when the initial passage was a translation that included the cognates than when it did not (13 msec shorter in the gaze duration data and $31 \mathrm{msec}$ shorter in the total time data), whereas the more skilled bilinguals tended to have longer fixation durations on second-passage cognates in the translationwith-cognates condition ( $8 \mathrm{msec}$ longer in the gaze duration data and $18 \mathrm{msec}$ longer in the total time data). Neither of the Newman-Keuls comparisons was significant in the gaze duration data. The 31-msec facilitation in the total time measure for the less skilled bilinguals was significant $[q(2,96)=2.87, p<.05]$, although the $18-\mathrm{msec}$ inhibitory trend for the more skilled bilinguals was not $[q(2,96)=1.67$, n.s. $]$. Furthermore, the cognate facilitation effect for the less skilled bilinguals in the total time data depended on the language of the second passage. It was significant for French test passages $[q(2,48)=3.09$, $p<.05]$ but was not significant when the second passages were in English $[q(2,48)=0.67$, n.s. $]$. The three-way interaction in the total time data approached significance $\left[F(1,96)=3.06, M S_{\mathrm{e}}=5,821, p<.09\right]$. No other effects were significant.

Translation with cognates versus identical. This comparison examined how language context influences transfer for repeated cognates. A main effect of initial passage type was observed for both gaze duration $[F(1,96)=$ $\left.8.48, M S_{\mathrm{e}}=1,449, p<.01\right]$ and total time $[F(1,96)=$ $\left.5.48, M S_{\mathrm{e}}=7,118, p<.05\right]$. Second-passage cognates were read more quickly when they had appeared in an identical first passage than when they had appeared in a first passage that was a translation of the second passage. None of the interactions were significant in the gaze duration data. For total fixation time, there was a significant three-way interaction between initial-passage type, language skill, and second-passage test language $\left[F(1,96)=7.39, M S_{\mathrm{e}}=7,118, p<.01\right]$, and therefore, the more skilled and the less skilled groups were analyzed separately. The more skilled bilinguals exhibited a main effect of initial-passage type $\left[F(1,48)=5.92, M S_{\mathrm{e}}=\right.$ $5,851, p<.05]$ and no interaction with language of the test passage. In contrast, the less skilled bilinguals did not 
exhibit a main effect of initial-passage type $[F(1,48)=$ 1.04, n.s.] but, instead, produced a significant interaction of initial-passage type and test language $[F(1,48)=5.04$, $\left.M S_{\mathrm{e}}=8,384, p<.05\right]$. Facilitation was observed for cognates preceded by an identical passage, as compared with a translated initial passage, only when the test passages were in English $[q(2,48)=3.28, p<.05]$, and not when the test passages were in French $[q(2,48)=1.20$, n.s. $]$.

\section{DISCUSSION}

The present study investigated whether bilinguals draw on knowledge from a prior experience with a text in one of their languages when reading a text in the other language. One goal was to understand the nature of the memory representation that is formed when a text is read and to what extent it is language specific. A second goal was to understand more broadly how bilinguals' exposure to print in one language might influence their reading ability in their other language.

The results from the present study provide evidence that the memory representations of the initial texts were, at least in part, in a meaning-based form that was not language specific. For both more and less skilled bilinguals, second-passage reading times were shorter when the first passages were translations with synonyms than when they were unrelated passages, regardless of the language of the initial passage. This finding provides evidence that meaning can transfer independently of surface form. There was, however, evidence that the memory representation also contained some details of the language of the text, because there was less cross-language transfer than withinlanguage transfer. Second-passage reading times were longer when first passages were translations with cognates than when they were identical, except for the less skilled bilinguals when the second passage was in French.

Of particular interest, fixation latencies on cognates in the second passages were analyzed to examine crosslanguage word-level transfer. When there was no overlap in message between the members of the passage pairs, only the less skilled bilinguals showed any evidence of crosslanguage word-level transfer, and when found, it was inhibitory in nature. However, when the members of the passage pairs had the same message, both more skilled and less skilled bilinguals showed cross-language word-level transfer. We then examined whether this cross-language word-level transfer was due to repeated meaning or repeated orthographic form. Only the less skilled bilinguals exhibited a benefit of repeated orthographic form. In a replication of this experiment with skilled bilinguals only (Friesen, 2004), we also did not observe cross-language transfer of surface form.

Finally, we examined the impact of a change in language context on cognate transfer across passages with a shared message. Generally, there was less word-level transfer when language context changed. These findings indicate that word-level information can transfer across languages; however, whether it does or not depends on the skill of the bilinguals in their second language, the direction of transfer, and whether the passages share meaning.

\section{Theoretical Implications}

Given that cross-language word-level transfer was observed only in limited circumstances, Carr et al.'s (1989) abstract theory is not supported by the results of the present study. Simply repeating words across a pair of passages does not always facilitate performance on those words in the second passage. Levy et al.'s (1993) episodic view can account for some but not all of our findings. They suggested that readers form an episodic memory trace of a passage in which the text meaning is the distinguishing feature of the representation. The surface form is bound to the text's meaning, and therefore, word-level transfer is predicted to occur only when the meaning of the text is reinstated in a subsequent reading. However, here we found word-level transfer for less skilled bilinguals even when passages did not have any meaning overlap. Furthermore, this view predicts that the amount of transfer depends on the extent to which the initial episode is reinstated. Contrary to this prediction, when reading French second passages, the less skilled bilinguals showed a similar benefit from initial passages that were identical and initial passages that were English translations. This finding suggests that it is not solely the repetition of the entire text episode that produces maximal transfer but that reader characteristics, such as the ability to form a situation model, also influence the degree of transfer. Levy (2001) came to the same conclusion on the basis of an experiment with skilled monolingual readers in which she varied whether or not they were given titles to ambiguous passages.

Even though Raney's (2003) context-dependent representation model was developed to explain data from studies of transfer effects in monolinguals, it provides a good account of our overall reading time results here. According to his view, the magnitude of the transfer effect will increase as the degree of overlap between situation model, textbase, and surface form increases. Here, bilinguals read second passages more quickly when they were preceded by a translation with synonyms than when preceded by an unrelated passage. The translation with synonyms would likely result in a similar situation model but has a very different surface form from the second passage. Second passages were typically read even more quickly when the initial passage not only had the same message, but also shared surface form with the second passage (i.e., when the first passage was identical to the second).

Raney's (2003) context-dependent representation model can also account for some of the findings in our eye-tracking data. When passages differ in meaning, Raney claims that transfer effects depend on the quality of the situation model formed from the first passage. When a poor situation model is formed, the surface form is not tightly bound to the text representation, and words are free to transfer independently of meaning. Words will not transfer independently of meaning when a good situation model is formed. The only participants who would have been expected to form a poor situation model of the initial passages were the less fluent bilinguals when the initial passages were in French, and they were the only group to produce a cross-language cognate transfer effect when passages differed in meaning. However, Raney's 
model predicts that transfer effects will be facilitatory, and the transfer effect here was an inhibitory one. Raney et al. (1996, as cited in Raney, 2003; Raney et al., 2002) did not include a condition in their study of bilinguals in which passages were unrelated in meaning. However, an inhibitory effect was found in a monolingual study by Levy et al. (1995) when passages did not share meaning. Levy et al. suggested that words in the second passage that overlap with those in the first passage can recruit the memory representation of the first passage. When the first passage is thematically unrelated to the second and cannot be integrated with it, reading times in the second passage are lengthened. Since the number of overlapping target words here was very small, as compared with Levy et al.'s study, we looked for transfer at the word level, rather than at the level of the entire passage.

The context-dependent representation model predicts that word-level transfer effects will most likely be observed in a repeated-reading paradigm when pairs of passages share meaning. However, the magnitude of the transfer effect is expected to decrease as the degree of overlap between surface form or textbase is reduced, and translations do have very different surface forms. Both groups of bilinguals did have shorter fixation latencies on second-passage cognates when they were preceded by a translation with synonyms than when they were preceded by an unrelated passage, indicating cross-language meaning transfer. Of particular interest was whether there was an additional effect of repeated surface form. In Raney et al.'s (2000) study of monolinguals, there was little benefit of repeated surface form in paraphrased passages beyond the benefit of repeated meaning, suggesting that little cross-language transfer of surface form would be expected. This expectation is consistent with our results for the more skilled bilinguals, but not for the less skilled bilinguals. The less skilled bilinguals exhibited facilitation on cognates when they were preceded by a translation with cognates, as compared with when they were preceded by a translation with synonyms, particularly when second passages were in French. This pattern of data is consistent with the data from Raney et al.'s (1996, as cited in Raney, 2003; Raney et al., 2002) bilingual study. They observed shorter fixation latencies on second-passage cognates than on second-passage translation equivalents only when the bilinguals were less fluent and when second passages were in their weaker language. One possible explanation of our results is that the less fluent French readers may have been using word meanings from their English memory representations to interpret the French words and this was easier when the orthography matched. Our finding that the effect was more robust in the total time data suggests that repeated surface form allowed the less fluent bilinguals to more easily integrate cognate meanings into their memory representations of the French second passages. Note that because the second-passage fixation latencies in all the conditions were on cognates, this finding does not indicate simply that cognates are particularly easy to read when reading in a less familiar language.

Our finding that more skilled bilinguals did not show cross-language transfer of orthographic form suggests ei- ther that their representation of the initial texts did not include surface form information or that the surface form information was bound to the language of the text and was not recruited when they were reading in their other language. The latter alternative is more plausible, given our finding that transfer effects were greater in the identical condition, in which surface form was identical, than in the translation-with-cognates condition, in which the passages overlapped in message but had little overlap in surface form. Our findings, then, suggest how text representations might change as second-language competence develops. Surface form information appears to become more specific to the language of the text.

The less skilled bilinguals showed similar facilitation on French second passages when the initial passages were identical French passages and when they were English translations with cognates. If only similarity between the members of passage pairs influenced the amount of transfer, there should have been more transfer in the identical condition than in the translation-with-cognates condition, because in the latter condition there was substantially less overlap in surface form. Our finding could be explained by taking into account differences in the quality of the situation model in the two conditions. The less skilled bilinguals would have formed a much better situation model after reading the initial English passage than after reading the initial French passage. A good situation model that has little surface form overlap with the second passage may confer as much transfer benefit as a weaker situation model that has much more surface form overlap with the second passage.

Both the more and the less skilled bilinguals showed a similar amount of message-level transfer (i.e., translation with synonyms vs. unrelated) in the overall reading time data when the initial passages were in French, even though the less skilled bilinguals had a poorer understanding of these passages, as demonstrated by the results on the subsequent comprehension questions. One might have expected the more skilled bilinguals to show a larger message-level transfer effect from French than the less skilled bilinguals. However, it may have been the case that differences were attenuated because both groups were good readers in the language of the second passage.

\section{Implications for Bilingual Exposure to Print}

The text comprehension model described here provides a framework for understanding how exposure to print in one language might benefit reading in another language. The ability to create textbase representations from the surface form is likely to depend largely on language-specific reading experience, whereas the ability to develop situation models from textbase representations may benefit from reading experience in either language (Raney et al., 2002). This view is consistent with that of Cummins (1991), who proposed that lower level comprehension processes (e.g., lexical and syntactic analyses) are language specific and higher level processes (i.e., integration and comprehension) are language nonspecific. Our finding of substantial crosslanguage transfer of meaning is consistent with the view that higher level comprehension processes are language 
nonspecific. In our paradigm, had we found a facilitatory cognate transfer effect when the passages were unrelated in meaning, this would have suggested that practice in reading words in one language context can benefit reading words in the other language, at least in languages with cognates. However, neither bilingual group showed any such transfer to French after having read a passage in English. The less skilled bilinguals did show some evidence of having word representations that were not bound to the language context when reading French initial passages, but these had a small inhibitory effect on their reading of the same words in an English context. Further support for the idea that experience with print in one language has little impact on lower level processing in a second language comes from a study by Arab-Moghaddam and Sénéchal (2001). They found that parental reports of Persian-English bilingual children's exposure to print in one language were uncorrelated with word recognition ability in the other language, although within-language correlations between exposure to print and word recognition ability were significant. English and Persian do not share the same alphabet, however. It remains to be seen whether cross-language correlations would be stronger with pairs of languages that use the same alphabet. If the view above is correct, we might expect that once the children are able to form adequate textbase representations in each language, reading experience in one language will influence reading comprehension ability in the other language. Further research in this area would be very useful for parents and educators of bilingual children. Of particular concern to many is whether children's reading development in the language of the school will be helped or harmed by exposure to print at home in a different language.

\section{Conclusion}

Most work on bilingual language processing has focused on word and sentence processing. This research has explored a much less studied aspect of bilingual reading that is, the nature of the memory representations that bilinguals form when reading texts in each of their languages. The results not only are informative regarding processes and representations in bilingual reading, but also provide converging evidence that informs theories of text representation in general.

\section{AUTHOR NOTE}

This study is based on a Master's thesis by D.C.F., supervised by D.J. The research was supported by a grant from the Natural Sciences and Engineering Research Council of Canada to D.J. D.C.F. was supported by an Ontario Graduate Scholarship. We thank Marc Joanisse for the use of his eye-tracking equipment and his technical support. We also thank Mandy-Lee Gagné for assistance with French translation, Sharon Lapkin and the Modern Language Centre at the Ontario Institute for Studies in Education at the University of Toronto for the use of the Senior French Proficiency Test Package for French Immersion, and Betty Ann Levy for comments on an earlier draft. Correspondence should be addressed to D. Jared, Department of Psychology, University of Western Ontario, London, ON, N6A 5C2 Canada (e-mail: djjared@uwo.ca).

\section{REFERENCES}

Arab-Moghaddam, N., \& Sénéchal, M. (2001). Orthographic and phonological processing skills in reading and spelling in Persian/
English bilinguals. International Journal of Behavioral Development, 25, 140-147.

Baayen, H., Piepenbrock, R., \& Van Rijn, H. (1993). The CeleX lexical database. Philadelphia: University of Pennsylvania, Linguistic Data Consortium.

Bourassa, D. C., Levy, B. A., Dowin, S., \& Casey, A. (1998). Transfer effects across contextual and linguistic boundaries: Evidence from poor readers. Journal of Experimental Child Psychology, 71, 45-61.

CARR, T. H., \& BRown, J. S. (1990). Perceptual abstraction and interactivity in repeated oral reading: Where do things stand? Journal of Experimental Psychology: Learning, Memory, \& Cognition, 16, 731738

Carr, T. H., Brown, J. S., \& Charalambous, A. (1989). Repetition and reading: Perceptual encoding mechanisms are very abstract but not very interactive. Journal of Experimental Psychology: Learning, Memory, \& Cognition, 15, 763-778.

Chateau, D., \& Jared, D. (2000). Exposure to print and word recognition processes. Memory \& Cognition, 28, 143-153.

Content, A., Mousty, P., \& Radeau, M. (1990). BRUleX: Une base de données lexicales informatisée pour le français écrit et parlé [A computerized lexical database for the French language]. Année Psychologique, 90, 551-566.

Cristoffanini, P., Kirsner, K., \& Milech, D. (1986). Bilingual lexical representation: The status of Spanish-English cognates. Quarterly Journal of Experimental Psychology, 38A, 367-393.

Cummins, J. (1991). Interdependence of first- and second-language proficiency in bilingual children. In E. Bialystock (Ed.), Language processing in bilingual children (pp. 70-89). New York: Cambridge University Press.

Cunningham, A. E., \& Stanovich, K. E. (1990). Assessing print exposure and orthographic processing skill in children: A quick measure of reading experience. Journal of Educational Psychology, 82, 733-740.

Dijkstra, T., Van JaArsveld, H., \& Ten Brinke, S. (1998). Interlingual homograph recognition: Effects of task demands and language intermixing. Bilingualism: Language \& Cognition, 1, 51-66.

FAULKNER, H. J., \& LeVY, B. A. (1994). How text difficulty and reader skill interact to produce differential reliance on word and content overlap in reading transfer. Journal of Experimental Child Psychology, 58, 1-24.

FaUlKneR, H. J., \& LeVy, B. A. (1999). Fluent and nonfluent forms of transfer in reading: Words and their message. Psychonomic Bulletin \& Review, 6, 111-116.

Fletcher, C. R., \& Chrysler, S. T. (1990). Surface form, textbases, and situation models: Recognition memory for three types of textual information. Discourse Processes, 13, 175-190.

FRIESEN, D. (2004). Cross-language transfer of word and text level information in fluent reading. Unpublished master's thesis, University of Western Ontario, London.

Gerard, L. D., \& Scarborough, D. L. (1989). Language-specific lexical access of homographs by bilinguals. Journal of Experimental Psychology: Learning, Memory, \& Cognition, 15, 305-315.

KinTSCH, W., \& VAN DiJK, T. A. (1978). Toward a model of text comprehension and production. Psychological Review, 85, 363-394.

Kroll, J. F., \& De Groot, A. M. B. (Eds.) (2005). Handbook of bilingualism: A psycholinguistic approach. Oxford: Oxford University Press.

LEMHÖFER, K., \& DiJKsTRA, T. (2004). Recognizing cognates and interlingual homographs: Effects of code similarity in language-specific and generalized lexical decision. Memory \& Cognition, 32, 533-550.

LeVY, B. A. (2001). Text processing: Memory representations mediate fluent reading. In M. Naveh-Benjamin, M. Moscovitch, \& H. L. Roediger III (Eds.), Perspectives on human memory and cognitive aging: Essays in honour of Fergus Craik (pp. 83-97). New York: Psychology Press.

Levy, B. A., Barnes, L., \& Martin, L. (1993). Transfer of fluency across repetitions and across texts. Canadian Journal of Experimental Psychology, 47, 401-427.

Levy, B. A., \& Burns, K. I. (1990). Reprocessing text: Contributions from conceptually driven processes. Canadian Journal of Psychology, 44, 465-482.

Levy, B. A., Campsall, J., Browne, J., Cooper, D., Waterhouse, C., \& Wilson, C. (1995). Reading fluency: Episodic integration across 
texts. Journal of Experimental Psychology: Learning, Memory, \& Cognition, 21, 1169-1185.

Pollatsek, A., Raney, G. E., LaGasse, L., \& Rayner, K. (1995). The use of information below fixation in reading and visual search. In J. Henderson, M. Singer, \& F. Ferreira (Eds.), Reading and language processing (pp. 51-72). Hillsdale, NJ: Erlbaum.

RANEY, G. E. (2003). A context-dependent representation model for explaining text repetition effects. Psychonomic Bulletin \& Review, 10, 15-28.

Raney, G. E., Obeidallah, S. M., \& Miura, T. K. (2002). Text comprehension in bilinguals: Integrating perspectives on language representation and text processing. In R. R. Heredia \& J. Altarriba (Eds.), Bilingual sentence processing (pp. 165-183). Amsterdam: Elsevier.

RANEY, G. E., \& RAYNER, K. (1995). Word frequency effects and eye movements during two readings of a text. Canadian Journal of Experimental Psychology, 49, 151-172.

Raney, G. E., Therriault, D. J., \& Minkoff, S. R. B (2000). Repetition effects from paraphrased text: Evidence for an integrated representation model of text representation. Discourse Processes, 29, 61-81.

SÁncheZ-Casas, R., \& García-Albea, J. E. (2005). The representation of cognate and noncognate words in bilingual memory: Can cognate status be characterized as a special kind of morphological relation?
In J. F. Kroll \& A. M. B. De Groot (Eds.), Handbook of bilingualism (pp. 226-250). Oxford: Oxford University Press.

Second Language Institute and Modern Language Centre (1985-1988). Senior French proficiency test package for French immersion. Ottawa/Toronto: University of Ottawa and Ontario Institute for Studies in Education.

Stanovich, K. E. (1986). Matthew effects in reading: Some consequences of individual differences in the acquisition of literacy. Reading Research Quarterly, 21, 360-406.

Stanovich, K. E., \& Cunningham, A. E. (1992). Studying the consequences of literacy within a literate society: The cognitive correlates of print exposure. Memory \& Cognition, 20, 51-68.

Stanovich, K. E., \& Cunningham, A. E. (1993). Where does knowledge come from? Specific associations between print exposure and information acquisition. Journal of Educational Psychology, 85, 211-229.

Stanovich, K. E., \& West, R. F. (1989). Exposure to print and orthographic processing. Reading Research Quarterly, 24, 402-433.

van Hell, J. G., \& Dijkstra, T. (2002). Foreign language knowledge can influence native language performance in exclusively native contexts. Psychonomic Bulletin \& Review, 9, 780-789.

ZwaAn, R. A., \& Brown, C. M. (1996). The influence of language proficiency and comprehension skill on situation-model construction. Discourse Processes, 21, 289-327.

\section{APPENDIXA}

Example of a Set of Passages Used in the French Test Language Condition

For each second passage, each participant saw only one of the first passage types.

\section{Second Passage}

Lorsque Tom Thomson est décédé en 1917, très peu d'individus avaient réalisé l'influence qu'il aurait sur la société canadienne. À sa mort, Thomson avait gagné le respect de quelques pairs, mais le public n'avait pas encore découvert son talent. Même Thomson n'avait pas reconnu son rôle dans la création d'un nouveau genre d'art canadien.

Thomson a choisi de poursuivre le métier d' artiste que tard dans sa vie. Tout de même, se promener dans la nature était un de ses passe-temps. Lors de son enfance, il est devenu un excellent pêcheur. Il pouvait lancer sa ligne à pêche parfaitement. La location où sa ligne tombait était toujours sa cible projetée. Grâce à son expertise dans le domaine de la pêche, Thomson a pu gagner assez d'argent comme guide pour subvenir à sa passion pour l'art.

Thomson a passé plusieurs heures à s'asseoir en silence sur les bancs près des lacs du parc Algonquin. Il semblait content lorsqu'il se promenait dans un canot seul sur le lac. Une fois arrivé de l'un de ses voyages dans l'intérieur, il a apporté sa pagaie à une firme d'art commerciale où il travaillait. Il a ensuite rempli un large réservoir avec de l'eau et a pagayé doucement en regardant au loin.

Quelqu'un n'a seulement qu'à jeter un coup d'œil sur les œuvres de Thomson pour trouver l'appréciation pour les paysages du Nord de l'Ontario. Même si ses détracteurs croyaient que Thomson n'avait aucune théorie d'art, ses amis racontaient des histoires à propos de son besoin de refléter la vérité du moment dans ses œuvres. Thomson avait dit que un des meilleurs compliments qu'il pouvait recevoir était d'entendre les gens lui dire qu'ils se sentaient transportés par ses scènes.

À une époque où le Canada cherchait une identité nationale, les œuvres de Thomson a donné au pays un regard de son essence. Ses collègues ont clamé que Thomson a fourni au Canada une nouvelle perspective de lui-même et sa place dans le monde. Par contre, Thomson n'était jamais d'accord avec cette opinion. Il se voyait plutôt comme un homme qui aimait son pays. Suite à son accident mortel, les œuvres et la vie de Thomson ont inspiré la formation du groupe des sept qui a continué sa tradition en apportant la fierté et la conscience de Canada.

\section{First Passages}

\section{Translation With Cognates and Translation With Synonyms}

(The synonyms are in brackets)

When Tom Thomson died in 1917, very few individuals realized the influence (weight) that he would have on Canadian society. At his death, Thomson had won the respect (esteem) of a circle of peers, but the public had not yet discovered his talent (skill). Thomson himself had not recognized his role in the creation (launch) of a new form of Canadian art.

Thomson chose his career as an artist (painter) later on in his life. Even so, spending time in nature (outdoors) was one of his hobbies. During his childhood, he became an excellent fisherman. He could cast a line perfectly. The location (spot) that he hit was always his intended target. Thanks to his fishing expertise, Thomson was able to earn enough money as a guide to subsidize his passion (love) for art. 


\section{APPENDIX A (Continued)}

Thomson spent many hours sitting in silence (quietly) on the banks of Algonquin Park's lakes. He seemed content (happy) alone in a canoe on the lake. After he returned from one of his voyages (trips) into the interior, he brought his paddle to the commercial art firm where he was employed. He then filled a large (big) reservoir with water and began paddling softly while looking off into the distance.

One has only to look at Thomson's works to find an appreciation (delight) for Northern Ontario's landscapes. Even if his critics suggested that Thomson did not have a theory of art, his friends told stories of his need to reflect the truth of the moment (event) in his work. Thomson once said that the best compliments (praise) he could ever receive was to hear people say that they felt transported by his scenes (pictures).

During a period when Canada was searching for a national identity, Thomson's work gave the country a look into its essence (soul). His colleagues have said that Thomson provided Canada with a new perspective on itself and its place in the world. However, Thomson was never in agreement with this opinion (assessment). He simply saw himself as a man who loved his country. Following his fatal accident (mishap), Thomson's life and work inspired the formation (founding) of the group of seven that continued in his tradition by bringing pride and awareness to Canada.

\section{Different Story With Cognates}

Man against nature, the eternal struggle to stretch one's own limits. A rock climber's passion for his sport pushes him to climb higher and harder summits. He is not content to simply remain in the real world of the everyday, but needs the intense aspect of sport to discover the essence of self.

There are two phases of rock climbing: the ascension and the rappel. The two aspects of the sport require an appreciation of peril. An imprudent climber risks a serious accident or even death. A lack of concentration lasting only a moment can be fatal. Consequently, rock climbers learn the value of fear and gain a respect for the mountain.

An important lesson for a young rock climber is to learn how take care of the mountain. Climbing purists are of the opinion that the surface of the rocks should not be damaged by humans. Instead, rock climbers must look for fissures in the rock formation that were caused by millions of years of evolution. Rock climbers do not admire the scenes below them when climbing, but rather they focus only on the few meters that surround them, looking for the location of their next fissure.

The creation of a friendship occurs between two climbers when one climber places their safety in the hands of the other. It is not simply talent that will ensure that a climber will reach the summit successfully. It is also the trust that the rock climber places in the belayer. This is a large responsibility, but it is not without reward. It is the voyages within oneself and the sharing of discoveries that make it worthwhile.

Some climbers say that they feel "naked in front of the mountain". There is no article of clothing or sound that can hide them from the truth of themselves. There is only silence. In such a situation, they search for the influence that the mountain can have on them. Rock climbers do not climb in search of compliments from the world. Nevertheless, they demonstrate to the world that they are able, like an artist, to perform remarkable exploits.

\section{Unrelated English Passage}

In the early days of space exploration, people assumed that, by the new millennium, colonies would live on the moon and that meetings with extra-terrestrials would be commonplace. However, thirty-four years after Neil Armstrong took the first step on the moon, little advancement has been made to fulfill the hopes of what is now known as the space age.

For many people, the space program represented humanity's desire to explore unknown regions. The world's geography had been explored and now it was time to discover humanity's place in the universe. However, the vision was not only of the discovery, but also of taming the unknown by colonizing the newly-acquired planets. This was an opportunity to shed civilization's problems by creating a utopia elsewhere.

Space mania grew in the 1960s near Cape Canaveral, Florida, in the form of city expansions and the generation of new jobs. However, even before the landing, NASA suffered reductions. Political surveys indicated that Americans felt that space exploration prevented addressing pertinent social problems. Also, the feasibility of rebirth on another world was lowered by the limitations of technology.

The neighbouring cities of Cape Canaveral, like Rocket City, never recovered. They became ghost towns when the technicians and scientists moved to find work in other industries. Nevertheless, in no way had the world abandoned space exploration. Progress continues and knowledge is acquired. Unmanned probes are sent to Mars and the International Space Station orbits the Earth. It is the expectations and excitement for space that has diminished. The missions received public attention only if disasters occur.

The space age was replaced with the information age (or age of information). When space exploration cost the United States billions of dollars, companies found that money could be made by using the space technology to construct satellites. With the invention of the Internet, information was easily available. Humanity's need to explore the unknown was fulfilled through the exploration of cyberspace. However, when the Internet becomes too commonplace, where will our thirst for adventure bring us, perhaps back to the stars? 
APPENDIX B

Example of a Set of Multiple-Choice Questions Used After the Initial Passage

1. According to the passage, Thomson earned extra money as a:

(a) commercial fisherman.

(b) guide.

(c) park warden.

2. At his death, Thomson was:
(a) well known in Canada.
(b) admired by his peers.
(c) a member of the Group of Seven.

3. According to the passage, Thomson wanted his work to reflect:
(a) his emotions
(b) his vision of Canada.
(c) the reality of the landscapes.

(Manuscript received June 12, 2006;

revision accepted for publication November 29, 2006.) 